\title{
Lung Cancer pT1 TNM Finding v7
}

National Cancer Institute

\section{Source}

National Cancer Institute. Lung Cancer pT1 TNM Finding V7. NCI Thesaurus. Code C88868.

Lung cancer with a tumor size of $3 \mathrm{~cm}$ or less in greatest dimension, surrounded by lung or visceral pleura and without bronchoscopic evidence of invasion more proximal than the lobar bronchus (i.e., not in the main bronchus). The uncommon superficial tumor of any size with its invasive component limited to the bronchial wall, which may extend proximal to the main bronchus, is also classified as T1a. (from AJCC 7th Ed.) 